\title{
A TUTELA DO AMBIENTE E O PROBLEMA DO CONTROLE JURISDICIONAL DE POLÍTICAS PÚBLICAS: ENTRE O ATIVISMO E O PASSIVISMO
}

\author{
Ariadne Elloise Coelho ${ }^{1}$ \\ Luiz Gustavo Gonçalves Ribeiro
}

\begin{abstract}
RESUMO: O estudo tem por objetivo averiguar a judicialização de políticas públicas para a tutela do direito fundamental ao meio ambiente ecologicamente equilibrado e esclarecer os limites de atuação, em vista dos ditames constitucionais e da função do Poder Judiciário no Estado Democrático de Direito. A pesquisa, jurídico-teórica, é orientada pelo raciocínio lógicodedutivo, e conclui pela necessidade de repensar o exercício do controle judicial, amparado no direito e não no discurso meramente político.
\end{abstract}

Palavras-Chave: Proteção ambiental; políticas públicas; Poder Judiciário; pesquisa teórica.

\section{THE GUARANTEE OF THE ENVIRONMENT AND THE PROBLEM OF THE JURISDICTIONAL CONTROL OF PUBLIC POLICIES: BETWEEN ACTIVISM AND PASSIVISM}

\begin{abstract}
The purpose of this study is to investigate the judicialization of public policies for the protection of the fundamental right to the ecologically balanced environment and to clarify the limits of action in view of the constitutional dictates and the role of the judiciary in the democratic state of law. The research, which is legal-theoretical, is based on logicaldeductive reasoning and notes the need to rethink the exercise of judicial control, supported by law and not merely political discourse.
\end{abstract}

Keywords: Environmental protection; public policy; Judiciary Power; theoretical research.

\footnotetext{
${ }^{1}$ Mestre em Direito Ambiental e Desenvolvimento Sustentável pela Escola Superior Dom Helder Câmara. Especialista em Ciências Penais pela Pós-Graduação Lato Sensu do Instituto de Educação Continuada na Pontifícia Universidade Católica de Minas Gerais - IEC PUC Minas. Bacharela em Direito pelo Centro Universitário Newton Paiva. Endereço postal: Rua Francisco Dias Menezes, 93, Xangrilá, Contagem/MG. CEP 32186-230. Email: ariadne_elloise@hotmail.com

2 Pós-Doutor em Direito Constitucional pela Università Degli Studi di Messina/IT. Doutor e Mestre em Ciências Penais pela UFG. Professor da graduação e do Programa de mestrado em Direito Ambiental e Desenvolvimento Sustentável da Escola Superior Dom Helder Câmara. Promotor de Justiça em Belo Horizonte/MG. Endereço postal: Rua General Dionísio Cerqueira, 147/302, Gutierrez, Belo Horizonte/MG. Email: lgribeirobh@ gmail.com
}

Rev. de Direito Ambiental e Socioambientalismo | e-ISSN: 2525-9628 | Maranhão | v. 3 | n. 2 | p. 42 - 58 | Jul/Dez. 2017 


\section{INTRODUÇÃO}

A implementação dos direitos fundamentais, que demandam um comportamento positivo do Estado, sofre constantes boicotes dos poderes ordinariamente competentes, os quais desrespeitam a Constituição da República de 1988. E o meio ambiente ecologicamente equilibrado, caracterizado como um direito fundamental e dotado constitucionalmente de tutela, inclui-se nas omissões do Poder Público.

A dúvida é se, nesse contexto, é devida a intromissão do Judiciário para fazer colmatar a abstenção governamental e viabilizar a fruição plena dos direitos fundamentais socioambientais, e em qual (is) medida (s), eis que não há um debate aprofundado sobre a temática e a consolidação de pressupostos para a sua admissibilidade.

É que, ante a contumaz inércia do aparelho estatal, o apelo ao Judiciário tem só aumentado, esfera de poder cuja atuação passa a ser questionada em virtude de interesses puramente políticos, carecedores da legitimidade democrática, jurídica e processual.

A exposição das ideias é inaugurada com apontamentos sobre o reconhecimento do meio ambiente ecologicamente equilibrado como direito fundamental de todos, merecedor de proteção constitucional, com dimensões negativas e positivas. Também é explicitado que a fruição desse direito exige medidas implementadoras pelo Poder Público, muitas vezes negligenciadas por escusas orçamentárias.

Em continuidade, faz-se exposição sobre o controle judicial de políticas públicas, diante da inércia dos demais poderes, o que resulta em criação jurisprudencial do direito, com realce das principais discussões envolvendo a legitimidade da atuação, o entendimento consolidado no Supremo Tribunal Federal e a possibilidade de abrangência dos conteúdos socioambientais.

Por último, é feita uma reflexão sobre a importância dos riscos ambientais e a necessidade de compatibilização dessa proteção à luz da judicialização de políticas públicas, balizada por um poder corretivo e imparcial, sem correspondência com os extremos.

Pormenorizam-se conceitos e argumentos defendidos como apropriados para uma decisão judicial correta, na perspectiva da Constituição de 1988, bem como as dificuldades e desdobramentos que a matéria proporciona.

As conclusões e posicionamentos reproduzidos resultaram de uma pesquisa ligada à vertente jurídico-teórica, a partir do levantamento da produção normativa e doutrinária 
pertinente, com amparo no raciocínio lógico-dedutivo em que se tem a necessidade de tutela estatal do ambiente ecologicamente equilibrado, ainda que em última instância pelo Judiciário.

Espera-se que esta pesquisa possa contribuir com o debate a respeito da efetivação dos direitos socioambientais mediante a representatividade judicial, mormente diante de argumentos jurídico-democráticos, inclusive fomentando a efetiva consideração sobre a legitimação e devida intervenção do Judiciário brasileiro.

\section{MEIO AMBIENTE E UM "NOVO" MODO DE PENSAR OS DIREITOS FUNDAMENTAIS}

A Constituição da República Federativa do Brasil de 1988 elevou a questão ambiental a um patamar de proteção necessária à sadia qualidade de vida, incluindo o meio ambiente ecologicamente equilibrado, bem de uso comum do povo, como um direito fundamental já reconhecido internacionalmente na expressão de direitos humanos ${ }^{3}$.

Para Celso Antônio Pacheco Fiorilo (2014, p. 47), a Constituição revestiu a tutela do meio ambiente de novas características, ligadas aos direitos difusos, conceituados no artigo 81, parágrafo único, inciso I, da Lei 8.078/90 (Código de Defesa do Consumidor), como “[...] os transindividuais, de natureza indivisível, de que sejam titulares pessoas indeterminadas e ligadas por circunstâncias de fato” (BRASIL, 1990).

De acordo com o autor, "os grandes temas de conflitos de interesses estão adaptados não mais a situações iminentemente individuais, mas sim a conflitos coletivos" (FIORILLO, 2014, p. 37). O meio ambiente transcende o interesse individual, pois é uma preocupação e necessidade de todos.

De fato, o meio ambiente foi identificado como direito fundamental de terceira dimensão, em razão de seu caráter transindividual, na Conferência de Estocolmo de 1972 (THOMÉ, 2014, p. 122), como parte de um movimento construído após a ocorrência de diversas tragédias ambientais no mundo e as intensificadas discussões sobre o tema (COSTA, 2010, p. $35)$.

A respeito das classificações dos direitos fundamentais no constitucionalismo, Bernardo Gonçalves Fernandes (2013) explica que os direitos são agrupados em gerações de

\footnotetext{
${ }^{3}$ Segue-se, aqui, o entendimento abordado por Bernardo Gonçalves Fernandes (2013, p. 311) de que os direitos humanos são aqueles reconhecidos na esfera do direito internacional; enquanto os direitos fundamentais são os positivados pelo direito constitucional interno de cada país.
}

Rev. de Direito Ambiental e Socioambientalismo | e-ISSN: 2525-9628 | Maranhão | v. 3 | n. 2 | p. 42 - 58 | Jul/Dez. 2017 
direitos por meio de um processo histórico da tríade liberdade-igualdade-fraternidade empregada nas revoluções burguesas:

\begin{abstract}
Por isso mesmo, os direitos de primeira geração (ou dimensão para alguns) seriam chamados também de direitos de liberdade: direitos civis e políticos, que inaugurariam o constitucionalismo do Ocidente, no final do século XVIII e início do século XIX. Seu titular é, então, o indivíduo, ao passo que encontra no Estado o dever de abstenção. [...]. No curso do século XX, tem-se o surgimento dos direitos de segunda geração(dimensão). São eles: direitos sociais, culturais e econômicos. Os mesmos são chamados sociais não pela perspectiva coletiva, mas sim pela busca da realização de prestações sociais. (...). No final do século XX, um resgate do teor humanístico oriundo da tomada de consciência de um mundo partido entre nações desenvolvidas e subdesenvolvidas teria sido um elemento importante para o pensar de uma nova geração de direitos fundamentais, uma terceira geração de direitos (dimensão). Em uma leitura ainda mais expandida, enxerga como destinatário todo o gênero humano (presente e futuro), como um todo conectado, de modo que se fundamentaria no princípio da fraternidade (ou segundo alguns, no da solidariedade). (FERNANDES, 2013, p. 315- 316). (grifos no original)
\end{abstract}

Tomando as lições do constitucionalista Paulo Bonavides, Bernardo Gonçalves Fernandes (2013, p. 316 a 317) ainda cita os direitos de quarta geração, tais como o direito à informação e os direitos relacionados à biotecnologia, bem como uma quinta geração de direitos, titularizada pela paz e/ou amor.

Critica-se o termo geração, eis que daria a ideia equivocada de substituição dos direitos antigos pelos surgidos posteriormente. É válida a narrativa de Bernardo Gonçalves Fernandes sobre a questão:

Ora, uma leitura paradigmática (que defendemos) da questão nos mostra que tal ideia
é falsa, afinal a cada "geração" não só assistimos à inserção de novos direitos, mas
também a uma redefinição do sentido e do conteúdo dos direitos anteriormente
fixados. Isto é, a o falar em uma segunda geração de direitos, é inevitável que voltemos
olhares para os direitos de primeira geração e busquemos desenvolver uma leitura
compatibilizada e harmonizada desses dois níveis. Assim, não há como imaginar que,
por exemplo, a inclusão dos direitos sociais no texto constitucional não levou a uma
rediscussão sobre os direitos de liberdade ou de propriedade (FERNANDES, 2013, p.
316).

Importante destacar certo consenso, já por algum tempo, de que os direitos fundamentais não se restringem aos estabelecidos no artigo $5^{\circ}$ da Constituição de 1988, estando diluídos em outros títulos e capítulos, expressa ou implicitamente, até mesmo em razão da abertura concedida pelo $\S 2^{\circ}$, do citado dispositivo, que, em redação clara, assim dispõe: “os direitos e garantias expressos nesta Constituição não excluem outros decorrentes do regime e 
dos princípios por ela adotados, ou dos tratados internacionais em que a República Federativa do Brasil seja parte” (THOMÉ, 2014, p. 123).

E a previsão do direito ao meio ambiente equilibrado tem seu núcleo fundante no artigo 225 da Constituição de 1988, o qual prevê o direito de todos ao meio ambiente ecologicamente equilibrado, "bem de uso comum do povo e essencial à sadia qualidade de vida, impondo-se ao Poder Público e à coletividade o dever de defendê-lo e preservá-lo para as presentes e futuras gerações”, mas é referenciado em tantos outros dispositivos do texto constitucional (SILVA, 2013, p. 50-53).

Em geral, prevalece o entendimento de que o meio ambiente alcançou um patamar de direito fundamental, eis que imprescindível ao bem-estar humano e à fruição dos demais direitos fundamentais, pelas presentes e futuras gerações.

Rafaela Luiza Pontalti Giongo (2010, p. 87) aduz que o meio ambiente é direito fundamental na medida em que a sua proteção visa "uma melhor qualidade de vida da sociedade atual, mas também das futuras gerações, caracterizando-se assim como um direito transindividual e transgeracional".

Beatriz Souza Costa(2010) apresenta interessante trabalho ao erigir o meio ambiente como o próprio direito à vida, pois é o primeiro que confere ao último a dignidade e, portanto, o pleno desenvolvimento:

\footnotetext{
Dessa forma, o art. $5^{\circ}$, caput, consagra o direito à vida e o art. 225 protege essa vida antes que ela venha a ser concebida [...]. Como já foi comprovado alhures, o artigo supracitado é direito fundamental subjetivo, e o meio ambiente é um direito à vida que será reconhecido. [...] Nesse diapasão, é confortável afirmar neste trabalho que a proteção do direito a vida está garantido, sim, com "Vida antes da Vida". Ou melhor, o direito e proteção dos não nascidos está garantido na própria Constituição brasileira, quando expõe, em seu art. 225, o direito das gerações futuras. Portanto, não se pode esquecer de que um elemento importantíssimo nessa teoria é a solidariedade humana, explanada neste trabalho. [...] Evidencia-se, no artigo 225, um meio ambiente ecologicamente equilibrado que é essencial à sadia qualidade de vida. Qualidade de vida que deve ser compreendida como viver bem, de forma digna, em local fora de risco para a vida humana. [...] É correto afirmar que o direito à vida condiciona todos os demais direitos, mas o acesso a esse direito de defesa está intimamente ligado ao meio ambiente, que deve ser protegido de riscos ambientais sérios `avida. $\mathrm{O}$ meio ambiente também deve ser protegido como o direito de defesa da vida, ou melhor, como o local fundamental do desenvolvimento da personalidade humana. (COSTA, 2010, p. 95).
}

Constata-se, portanto, que a proteção ao meio ambiente é que irá garantir a permanência da existência humana, e uma existência pautada necessariamente na sadia 
qualidade de vida, motivo pelo qual as normas sobre direito ambiental precisam ser respeitadas (COSTA; REIS; OLIVEIRA, 2016, p. 139).

E, para tanto, o ordenamento jurídico brasileiro exige do Poder Público (e também da coletividade) ações tanto positivas quanto negativas. Isso porque o direito ao meio ambiente ecologicamente equilibrado engloba tanto características individuais (primeira geração) quanto coletivas (segunda geração), classificando-se como direito de terceira geração (THOMÉ, 2014, p. 133).

Na verdade, já surge uma tentativa, ainda que tímida, de difundir a dupla dimensão, positiva e negativa, de todos os direitos fundamentais, isto é, todos eles, mesmo que somente os direitos de primeira geração, “(...) possuem uma dimensão negativa e uma prestacional e que todos, sem exceção, 'custam recursos do erário '." (CRUZ, 2007, p. 335).

O professor Álvaro Ricardo de Souza Cruz esclarece, neste sentido, como importante o entendimento da relação de reciprocidade e complementariedade entre as relações negativas e positivas dos direitos fundamentais, que somente são separadas no discurso acadêmico no intuito de facilitar o aprendizado:

Dito de outro modo, não há como se pretender apartar os direitos individuais dos direitos sociais, como, por exemplo, na discussão da extensão das clausulas pétreas da Constituição (art. 60, $4^{\circ}$, inciso IV). De modo metafórico, é possível estudar de forma apartada os sistemas circulatório e respiratório do homem, mas, na prática, eles não podem subsistir um sem o outro. (CRUZ, 2007, p. 336-337).

Por certo que o reconhecimento do meio ambiente como direito fundamental não é mais o dilema, mas sim toda a problemática em torno da implementação dos direitos fundamentais, os sociais e, foco do presente estudo, os socioambientais, na medida em que são necessários recursos financeiros.

O Poder Público tem o dever, como explicitado algures, de efetivar os direitos fundamentais ambientais e o faz, sobretudo, por meio de políticas públicas. No entanto, como resolver a violação desses direitos fundamentais ante a omissão estatal na concretização das políticas públicas?

Rev. de Direito Ambiental e Socioambientalismo | e-ISSN: 2525-9628 | Maranhão | v. 3 | n. 2 | p. 42 - 58 | Jul/Dez. 2017 


\section{CONTROLE JURISDICIONAL DE POLÍTICAS PÚBLICAS SOCIOAMBIENTAIS}

A atuação estatal se efetiva por meio de instrumentos diversos com vistas à concretização das políticas públicas (THOMÉ, 2014, p. 159), inclusive por meio de cooperação com entidades não estatais e a própria iniciativa privada. Não obstante isso, o estado ainda constitui o principal ator social responsável por implementar os direitos, valendo-se, principalmente, das normas (Poder Legislativo), atos (Poder Executivo) e decisões (Poder Judiciário).

O mandamento constitucional impõe ao Poder Público o dever de proteger e preservar o meio ambiente ecologicamente equilibrado (BRASIL, 1988). A implementação desse dever, por meio de políticas públicas, incumbe, normalmente, aos Poderes Legislativo e Executivo, os quais elaboram e executam as atividades tendentes à consecução dos fins do Estado, o que não exclui a intervenção - quando necessária - do Poder Judiciário (THOMÉ, 2014, p. 211).

A Constituição de 1988 consagrou os objetivos fundamentais da República Federativa do Brasil no artigo $3^{\circ}$, dentre os quais se destacam aqueles previstos nos incisos I e III: "construir uma sociedade livre, justa e solidária" e "erradicar a pobreza e a marginalização e reduzir as desigualdades sociais e regionais" (BRASIL, 1988). Com efeito, exigem políticas sociais, como nas áreas da saúde, educação e meio ambiente sadio, passíveis de desrespeito pelo Legislativo e Executivo.

Para que esses objetivos do Estado brasileiro sejam atingidos, faz-se essencial a atuação de todas as formas de expressão do poder estatal, tidas como instrumentos para a obtenção dos seus fins. Com efeito, para Ada Pellegrini Grinover:

[...] no Estado Democrático de Direito, o Judiciário, como forma de expressão do poder estatal, deve estar alinhado com os escopos do próprio Estado, não se podendo mais falar numa neutralização de sua atividade. Ao contrário, o Poder Judiciário encontra-se constitucionalmente vinculado à política estatal. (GRINOVER, 2013, p. 129).

É defensável, então, a legitimidade de implementação de políticas públicas pelo Poder Judiciário na hipótese de conflitos concernentes às violações de direitos fundamentais decorrentes da inoperância ou irregularidade dos Poderes Legislativo e Executivo.

E o próprio Judiciário tem entendido dessa forma em diversos julgados do Supremo Tribunal Federal - RTJ 174/687; RTJ 175/1212-1213; RTJ 199/1219-1220; AI 583.136/SC; RE 
503.658/SC; ADPF 45/DF. Transcreve-se, por oportuno, manifestação da Ministra Carmen Lúcia sobre o assunto:

Ao contrário do que decidido pelo Tribunal 'a quo', no sentido de que a manutenção
da sentença provocaria ingerência de um em outro poder, a norma do art. 227 da
Constituição da República impõe aos órgãos estatais competentes - no caso
integrantes da estrutura do Poder Executivo - a implementação de medidas que
lhes foram legalmente atribuídas. Na espécie em pauta, compete ao Estado, por
meio daqueles órgãos, o atendimento social às crianças e aos adolescentes vítimas de
violência ou exploração sexual. Tanto configura dever legal do Estado e direito das
vítimas de receber tal atendimento. $[\ldots]$

É competência do Poder Judiciário, vale dizer, dever que lhe cumpre honrar, julgar as causas que lhe sejam submetidas, determinando as providências necessárias à efetividade dos direitos inscritos na Constituição e em normas legais.

$[\ldots]$

Exatamente na esteira daquela jurisprudência consolidada é que cumpre reconhecer o dever do Estado de implementar as medidas necessárias para que as crianças e os adolescentes fiquem protegidos de situações que os coloquem em risco, seja sob a forma de negligência, de discriminação, de exploração, de violência, de crueldade ou a de opressão, situações que confiscam o mínimo existencial sem o qual a dignidade da pessoa humana é mera utopia. E não se há de admitir ser esse princípio despojado de efetividade constitucional, sobre o que não mais pende discussão, sendo o seu cumprimento incontornável.

10. Reitere-se que a proteção contra aquelas situações compõe o mínimo existencial, de atendimento obrigatório pelo Poder Público, dele não podendo se eximir qualquer das entidades que exercem as funções estatais, posto que tais condutas ilícitas afrontam o direito universal à vida com dignidade, à liberdade e à segurança. (grifos nossos) (AI 583.136/SC).

Destaca-se que o Supremo Tribunal Federal não ignora a necessidade de compatibilizar a implementação de políticas públicas pelo Judiciário com alguns requisitos, como o limite orçamentário estatal, o que também não poderá servir de artifício perpétuo e arbitrário para frustrar o cumprimento de obrigações constitucionais fundadas no mínimo existencial.

Caso contrário, o caráter programático de determinadas normas constitucionais servirá de muleta e abstenção injustificada do Poder Público, posto sob o falso argumento de serem desprovidas de eficácia jurídica, tornando-se mera promessa.

O ministro Celso de Melo, nas oportunidades em que teve de julgar o tema, reafirmou o dever institucional do Judiciário de agir positivamente diante da ofensa constitucional dos demais poderes, sob pena de também infringir a autoridade da Lei suprema ao se quedar inerte em função de conceitos ultrapassados de jurisdição.

DESRESPEITO À CONSTITUIÇÃO - MODALIDADES

$\mathrm{DE}$ 


\section{COMPORTAMENTOS INCONSTITUCIONAIS DO PODER PÚBLICO.}

- O desrespeito à Constituição tanto pode ocorrer mediante ação estatal quanto mediante inércia governamental. A situação de inconstitucionalidade pode derivar de um comportamento ativo do Poder Público, que age ou edita normas em desacordo com o que dispõe a Constituição, ofendendo-lhe, assim, os preceitos e os princípios que nela se acham consignados. Essa conduta estatal, que importa em um 'facere' (atuação positiva), gera a inconstitucionalidade por ação.

- Se o Estado deixar de adotar as medidas necessárias à realização concreta dos preceitos da Constituição, em ordem a torná-los efetivos, operantes e exequíveis, abstendo-se, em consequiência, de cumprir o dever de prestação que a Constituição lhe impôs, incidirá em violação negativa do texto constitucional. Desse 'non facere' ou 'non praestare', resultará a inconstitucionalidade por omissão, que pode ser total, quando é nenhuma a providência adotada, ou parcial, quando é insuficiente a medida efetivada pelo Poder Público.

[...]

A omissão do Estado - que deixa de cumprir, em maior ou em menor extensão, a imposição ditada pelo texto constitucional - qualifica-se como comportamento revestido da maior gravidade político-jurídica, eis que, mediante inércia, o Poder Público também desrespeita a Constituição, também ofende direitos que nela se fundam e também impede, por ausência de medidas concretizadoras, a própria aplicabilidade dos postulados e princípios da Lei Fundamental. (Grifos nossos) (RTJ 185/794-796, Rel. Min. CELSO DE MELLO, Pleno).

E:

Embora resida, primariamente, nos Poderes Legislativo e Executivo, a prerrogativa de formular e executar políticas públicas, revela-se possível, no entanto, ao Poder Judiciário, determinar, ainda que em bases excepcionais, especialmente nas hipóteses de políticas públicas definidas pela própria Constituição, sejam estas implementadas pelos órgãos estatais inadimplentes, cujaomissão - por importar em descumprimento dos encargos político-jurídicos que sobre eles incidem em caráter mandatório - mostra-se apta a comprometer a eficácia e a integridade de direitos sociais e culturais impregnados de estatura constitucional. (RTJ 199/1219-1220, Rel. Min. CELSO DE MELLO) (grifos nossos).

A possibilidade de judicialização de politicas públicas, no entanto, é ainda tema bastante controverso na doutrina e recheado de críticas sobre aspectos parcelares, mas de suma importância, condizentes à interferência na discricionariedade administrativa; ao déficit orçamentário estatal e à deturpação da teoria da separação dos poderes.

No entanto, nota-se que a discricionariedade também é objeto de revisão judicial no que concerne à extrapolação legal e a ofensa aos demais princípios constitucionais, como a impessoalidade e moralidade (THOMÉ, 2014, p. 219). Aliás, a Lei da Ação Popular já previu análise do mérito administrativo pelo Judiciário apenas com a lesividade, dispensando o requisito da ilegalidade (BRASIL, 1965); e a Constituição de 1988 (artigo 5º, inciso LXXIII)

Rev. de Direito Ambiental e Socioambientalismo | e-ISSN: 2525-9628 | Maranhão | v. 3 | n. 2 | p. 42 - 58 | Jul/Dez. 2017 
confirmou a apreciação do mérito administrativo no ato lesivo à moralidade administrativa (BRASIL, 1988).

Álvaro Ricardo alerta que a omissão na implementação dos direitos sociais vem comumente ligada ao equivocado discurso liberal de que os direitos sociais, ao contrário dos individuais, sofrem pela falta de recursos públicos; mas a efetivação de direitos individuais também requisita dinheiro, como a manutenção das forças policiais na segurança das pessoas (CRUZ, 2007, p. 335-336).

Para o autor, "por detrás desse discurso, presencia-se no país uma violenta exclusão de cidadania das pessoas mais desfavorecidas, vítimas das mais diversas formas de violência física, simbólica ou moral (...)”(CRUZ, 2007, p. 334-335).

Na visão de Ada Pellegrini, imprescindível a mudança de paradigma, com adequação da realidade (fática e jurídica) brasileira ao Estado Democrático de Direito, incluindo o Poder Judiciário como coautor na consecução dos objetivos do Estado. (GRINOVER, 2013, p. 128129). Claro que ainda permanecem dúvidas quanto ao limite dessa atuação, no que se inserem a razoabilidade e reserva do possível, as ações próprias ao controle e o indefinido e polêmico mínimo existencial (GRINOVER, 2013, p. 132).

Além de envolver direitos tanto individuais como sociais, conforme explicitado algures, Romeu Thomé defende a intervenção do Judiciário com base na proibição do retrocesso socioambiental. Segundo ele, pretende-se que o legislador e/ou o administrador público, no exercício de suas atribuições, "seja sempre conduzido pelo objetivo de não suprimir ou reduzir o grau de intensidade normativa que os direitos socioambientais já tenham alcançado" (THOMÉ, 2014, p. 206), e, caso isso ocorra, contrariando a norma constitucional protetiva, caberá ao Judiciário restaurar "[...] a normatividade constitucional e a correção de disfuncionalidades do sistema de representação política". (THOMÉ, 2014, p. 206-210).

Dessa forma, no contexto contemporâneo, o Poder Judiciário desponta com a importante missão, embora a posteriori e corretiva, de tutelar os direitos e deveres socioambientais, sem que essa moderna e árdua tarefa se transmude em decisões descuidadas e tiranas.

Rev. de Direito Ambiental e Socioambientalismo | e-ISSN: 2525-9628 | Maranhão | v. 3 | n. 2 | p. 42 - 58 | Jul/Dez. 2017 


\section{ENTRE O ATIVISMO TIRANO E O PASSIVISMO JUDICIAL}

Sem dúvida, a maior preocupação por trás das críticas feitas à possibilidade de o Judiciário implementar políticas públicas, via decisão substitutiva da conveniente omissão dos poderes estatais frente às suas obrigações constitucionais, é a de que haja uma verdadeira tirania judicial.

É o medo apresentado por Lenio Streck, embora em estudo mais amplo do abordado neste trabalho, de que ocorra apenas uma troca do juiz "boca da lei" por um que se torna a "boca que pronuncia o discurso (prévio) de fundamentação”. (STRECK, 2006, p. 247).

Há hoje uma ideia de que o Judiciário é o grande guardião da moralidade. Tanto que impera uma crise de representatividade e responsabilidade nos outros poderes, em que o legislativo e executivo deixam matérias relativas à proteção dos direitos fundamentais e de grupos vulneráveis para resolução judicial.O perigo disso é a utilização das decisões judiciais como programas de ação política e instrumentos de governo.

O problema todo é que as decisões têm sido políticas e não jurídicas. Afinal, será que o Direito tem sido utilizado legitimamente, adequado aos anseios sociais (e ambientais) ou têm prevalecido interesses espúrios? E mais, "validados" por um funcionalismo classista, moralista e preconceituoso, que encontra no ativismo (arbítrio) judicial o melhor desafogo para os seus vícios.

Prepondera entre os juristas (profissionais do direito), de forma geral, uma tomada de decisão confortável, partindo-se da análise superficial da situação e de premissas equivocadas: ou entende-se, de antemão, que existe conflito entre dois únicos princípios, desconsiderando a integridade do direito e demais princípios envolvidos; ou já se tem uma pré-concepção sobre o tema, e busca-se por argumentos que justifiquem a opção pré-formulada (decisões pareceristas).

Ada Pellegrini aponta a superação de dogmas liberais como o da superioridade da atividade legislativa e o da representação do juiz à simples la bouche de la loi. (GRINOVER, 2013, p. 128). No Estado Democrático de Direito, não se pode permitir a prevalência arbitrária de nenhum dos poderes, que devem ser constantemente (re) equilibrados em suas funções. Retroceder na história não é uma hipótese.

O ideal democrático está configurado na vontade popular, com participação, direta ou indiretamente, na formulação de normas, impostas ao próprio Estado (artigo $1^{\circ}$ da Constituição de 1988), que deve (ou deveria) servir como paradigma de "práticas jurídicas contemporâneas",

Rev. de Direito Ambiental e Socioambientalismo | e-ISSN: 2525-9628 | Maranhão | v. 3 | n. 2 | p. 42 - 58 | Jul/Dez. 2017 
com a observância da Constituição e a participação da sociedade em todo o processo e formulação das decisões. (FERNANDES, 2013, p. 288-289).

No caso do Judiciário, a legitimidade democrática na decisão de política pública “decorre da participação igualitária das partes no processo mediante o contraditório, bem como do conteúdo de direitos fundamentais do qual se revestem as políticas públicas, o que autoriza sua judicialização.” (ZUFELATO, 2013, p. 313).

Ora, a garantia de que lesão ou ameaça a direito seja apreciada pelo Judiciário também constitui um direito fundamental (artigo $5^{\circ}$, inciso XXXV) (BRASIL, 1988), assim como o é a melhor resposta no curso do andamento processual recebida pelo cidadão (CRUZ, 2007, p. 241).

Por tudo que se evidenciou, diante de condutas ofensivas aos ditames constitucionais, não faz sentido a adoção de pura passividade pelo Judiciário, eis que existiria uma dupla ofensa à sociedade: a omissão legislativa ou executiva, e uma omissão última, a judicial. Como proceder, então?!

Trabalha-se a concepção de princípios de Ronald Dworkin, transportada para o ordenamento jurídico ocidental, em que o Direito possui caráter deontológico, devendo ser reconstruído argumentativamente em cada caso e decisão, com ponderação e não sobreposição (VILELA; FRANÇA, 2014, p. 125-126). É que o autor diferencia argumentos de princípio e argumentos de política:

Os argumentos de política justificam uma decisão política, mostrando que a decisão fomente ou protege algum objetivo coletivo da comunidade como um todo. [...] Os argumentos de princípio justificam uma decisão política, mostrando que a decisão respeita ou garante um direito de um indivíduo ou de um grupo. (DWORKIN, 2002, p. 129)

Mais:

O direito como integridade pressupõe, contudo, que os juízes se encontram em situação muito diversa daquela dos legisladores. [...] Os juízes devem tomar suas decisões sobre o "common law" com base em princípios, não em política: devem apresentar argumentos que digam por que as partes realmente teriam direitos e deveres legais "novos" que eles aplicaram na época em que essas partes agiram, ou em algum outro momento pertinente do passado. (DWORKIN, 1999, p. 292-293)

Assim, como esclarece Igor Suzano Machado (2016), segundo Dworkin, o trabalho dos juízes deve ser orientado "primordialmente por argumentos de princípio, enquanto 
legisladores e chefes do Poder Executivo, por mais que condicionados também por princípios, estariam livres para trabalhar com argumentos de política ainda não explicitados em lei" (MACHADO, 2016, p. 248).

A aplicação do Direito requer argumentos de princípio, do que é juridicamente devido, não se utilizando de argumentos de política, cuja decisão cabe ao legislador, representante de nossa sociedade.

Para Álvaro Ricardo, o ativismo "se caracteriza no instante em que o julgador arroga a si o direito de ponderar fins e meios de forma utilitarista, com emprego de argumentos pragmáticos, isso é, por meio de argumentos de política”. (CRUZ, 2007, p. 266). Ademais:

Por isso, visualizar somente a questão do déficit orçamentário é reduzir os direitos fundamentais aos argumentos de política, desprezando os argumentos de princípios, o que é inaceitável, homologando o que os Governantes querem, seja o que for. (CRUZ, 2007, p. 378). O que também não autoriza, por si só, fechar os olhos para as consequências de cada decisão, mas sem antecipação do discurso, e sim na perspectiva de uma construção democrática do decisum.

Álvaro Ricardo explica que há “"[...] ameaça de uma ditadura judicial - e no sentido não apenas de uma ditadura de juízes, mas uma ditadura na qual os juízes dão um 'verniz' de legitimidade aos atos dos governantes sejam eles quais forem.” (CRUZ, 2007, p. 260). Para o autor, a saída é:

[...] a compreensão de um processo que ocorra dialogicamente, garantindo a participação das partes, do juiz, de peritos e seus assistentes e muitas vezes de terceiros, como nos casos de amicuscúriae, é fundamental. Aqui o conceito de uma comunidade de princípios de Dworkin ganha relevância, assim como também a perspectivade que Hércules não representa a figura de um super juiz, mas indica a necessidade da construção discursiva do processo. (CRUZ, 2007, p. 357).

Portanto, acredita-se que o Judiciário possa cumprir seu dever institucional, desde que vinculado às noções de imparcialidade e igualdade, e diametralmente desvinculado de qualquer forma de ativismo ou de passivismo, ambos rejeitados no Estado Democrático de Direito.

E é a Constituição da República Federativa do Brasil de 1988, norma suprema do ordenamento jurídico, que traça a base principiológica de direitos e garantias a serem observados, com as necessárias adaptações, por todos os microssistemas.

O direito ambiental também possui seus princípios próprios, os quais são aferidos perante a Constituição e todo o sistema jurídico. Fato é que o Judiciário deve atender aos

Rev. de Direito Ambiental e Socioambientalismo | e-ISSN: 2525-9628 | Maranhão | v. 3 | n. 2 | p. 42 - 58 | Jul/Dez. 2017 
postulados constitucionais ambientais, pois as decisões que dizem respeito ao meio ambiente podem balizar efeitos literalmente desastrosos.

É preciso que os aplicadores últimos do direito julguem com temperança diante de demandas envolvendo atos causadores (ou potencialmente causadores) de um desequilíbrio ambiental, pois o real alcance e proporção dos impactos são ainda desconhecidos à ciência humana. Sobretudo porque a balança na seara do meio ambiente tende constantemente para o crescimento econômico e não para a preservação ambiental e equidade social.

\section{CONSIDERAÇÕES FINAIS}

O desenvolvimento histórico e social do homem permitiu o reconhecimento, ao longo de lutas e conquistas, de direitos fundamentais, essenciais a uma vida de qualidade, entre os quais se destacou o do meio ambiente ecologicamente equilibrado, tido como pressuposto para o exercício dos demais direitos.

A proteção constitucional conferida ao meio ambiente impôs obrigações ao Poder Público que, no entanto, vem se omitindo com frequência, inviabilizando a sua implementação, ou mesmo agindo de forma a prejudicar e causar desequilíbrios.

E a desculpa reiterada dos agentes políticos se esvai na justificativa quase automática de ausência ou dificuldade financeira diante do dever de efetivar direitos com viés social, isto é, que exigem prestações positivas.

Essas abstenções do Estado, ora pelo Poder Legislativo ora pelo Poder Executivo, traduzindo-se em ameaças ou lesões ao direito fundamental socioambiental, têm sido levadas ao judiciário em busca da concretização da garantia perseguida pelo constituinte.

Enquanto parte indissociável do Poder Público, o Judiciário possui o dever institucional de suprir esse encargo postergado indefinidamente pelos demais poderes, cuja legitimidade tem fundamento no resguardo dos próprios preceitos da Constituição.

A atuação judicial no âmbito de políticas públicas não ofende os postulados do Estado Democrático de Direito, antes os reforçam, eis que é a maneira de corrigir distorções (in) convenientes e (in) oportunas do estado e reestabelecer a integridade normativa.

O que não pode mais ocorrer (nunca pôde) é a intervenção arbitrária do judiciário, o que se vê acima do bem e do mau, e decide como governante e não jurista. A especificidade do 
meio ambiente, essencial à vida do homem e dos demais seres vivos, exige a tratativa séria das demandas reclamadas, com a utilização de argumentos de princípios e não de política.

O controle jurisdicional adequado de políticas públicas está entre o ativismo tirano e o passivismo inaceitável, e depende de uma reflexão e mudança do modo de pensar e decidir no país, com consciência e responsabilidade dos efeitos colaterais. Do contrário, coloca-se em xeque a democracia e, antes de tudo, a vida saudável e equilibrada.

\section{REFERÊNCIAS}

BARROSO, Luís Roberto. Interpretação e aplicação da constituição:fundamentos de uma dogmática constitucional transformadora. 7. ed. rev. São Paulo: Saraiva, 2009.

BRASIL, Assembleia Nacional Constituinte. Constituição da República Federativa do Brasil. Brasília: Imprensa Nacional. Diário Oficial da União, 05 de outubro de 1988. Disponível em: <http://www.planalto.gov.br/ccivil03/constituicao/constitui\% C3\%A7ao.htm>. Acesso em: 10 abr. 2017.

BRASIL, Congresso Nacional. Lei n. 4.717, de 29 de junho de 1965. Brasília: Imprensa Nacional. Diário Oficial da União, 5 de julho de 1965. Disponível em: <http://www.planalto.gov.br/ccivil_03/leis/L4717.htm>. Acesso em: 10 abr. 2017

BRASIL. Supremo Tribunal Federal. ADPF 45 MC/DF. Rel. Min. Celso de Mello. 2004. Disponível em: <http://www.stf.jus.br/arquivo/informativo/documento/informativo345.htm>. Acesso em: 5 abr.. 2017.

CANOTILHO, José Joaquim Gomes. Direito constitucional e teoria da Constituição. 7ed. Coimbra: Edições Almedina, 2003.

CHAMON JR., Lúcio. Paradigma e aplicação do direito:por uma compreensão constitucionalmente adequada do Direito Penal sob a perspectiva de um caso concreto.Revista de Informação Legislativa, Brasília: v. 39, n. 155, p. 77-91, julho/setembro de 2002.

COSTA, Beatriz Souza. Meio ambiente como direito à vida:Brasil, Portugal, Espanha. Belo Horizonte: Editora O Lutador, 2010.

COSTA, Beatriz Souza; REIS, Emilien Vilas Boas; OLIVEIRA, Márcio Luís. Fundamentos filosóficos e constitucionais do direito ambiental. Rio de Janeiro: Lumen Juris, 2016.

CRUZ, Álvaro Ricardo de Souza. Hermenêutica jurídica e(em) debate. O constitucionalismo brasileiro entre a teoria o discurso e a ontologia existencial. Belo Horizonte: Forum, 2007.

DIAS, Jorge de Figueiredo.O direito penal na "sociedade de risco". Temas básicos da doutrina penal-sobre os fundamentos da doutrina penal; sobre a doutrina geral do crime, Coimbra: Coimbra Editora, 2001, p. 155-185.

Rev. de Direito Ambiental e Socioambientalismo | e-ISSN: 2525-9628 | Maranhão | v. 3 | n. 2 | p. 42 - 58 | Jul/Dez. 2017 
DWORKIN, Ronald. Levando o direito a sério. Tradução Nelson Boeira. São Paulo: Martin Fontes, 2002. 1999.

O império do direito. Tradução Jefferson Luiz Camargo. São Paulo: Martins Fontes,

FERNANDES, Gonçalves Bernardo. Curso de direito constitucional. 5ed. Salvador: JusPodivm, 2013.

FIORILlO, Celso Antônio Pacheco. Curso de direito ambiental brasileiro. São Paulo: Saraiva, 2014.

FULGÊNCIO, Paulo Cesar. Glossário VadeMecum: administração pública, ciências contábeis, direito, economia, meio ambiente. Rio de Janeiro: Mauad, 2007.

FURLAN, Fabiano Ferreira. O debate entre John Rawls e Jurgen Habermas sobre a concepção de justiça. Coleção Professor Álvaro Ricardo de Souza Cruz. Belo Horizonte: Arraes Editores, 2013. Vol. 5.

GRINOVER, Ada Pelegrini; WATANABE, Kazuo (Coord.). O controle jurisdicional de políticas públicas. 2. ed. Rio de Janeiro: Forense, 2013.

LAKATOS, Eva Maria; MARCONI, Marina de Andrade. Metodologia científica. 4 ed. São Paulo: Atlas, 2006.

MACHADO, Paulo Affonso Leme. Direito ambiental brasileiro. 22 ed. São Paulo: Malheiros, 2014.

MACHADO, Igor Suzano. Comunidade de princípios e princípio responsabilidade: o juiz Hércules confuso diante de uma natureza ameaçada. Revista Veredas do Direito, Belo Horizonte, v. 13, n. 27, p. 243-265, set./ dez. 2016. Disponível em: <http://www.domhelder.edu.br/revista/index.php/veredas/article/view/860/524>. Acesso em: 10 abr. 2017.

MILARÉ, Édis. Direito do ambiente: doutrina, jurisprudência, glossário. 7ed. São Paulo: Editora Revista dos Tribunais, 2011.

NEVES, Rodrigo Fernandes das. Ativismo judicial: objeções à intervenção do judiciário na formulação e execução de políticas públicas ambientais. Disponível em: http://www.procuradoria.al.gov.br/centro-de-estudos/teses/xxxv-congresso-nacional-deprocur adores-de-estado/direito-ambiental/ATIVISMO\%20JUDICIAL\%20-\%20OBJECOES\%20A \%20INTERVENCaO\%20DO\%20JUDICIARIO\%20NA\%20FORMULACaO\%20E\%20EXE CUCaO\%20DE\%20PO LITICAS\%20PUBLICAS.pdf>. Acesso em: 4 abr. 2017.

SILVA, José Afonso da. Direito ambiental constitucional. 10. ed. São Paulo: Malheiros, 2013.

Rev. de Direito Ambiental e Socioambientalismo | e-ISSN: 2525-9628 | Maranhão | v. 3 | n. 2 | p. 42 - 58 | Jul/Dez. 2017 
SILVA, José Afonso da. Curso de direito constitucional positivo. 31 ed. rev. e atual. São Paulo: Malheiros Editores, 2008.

STRECK, Lênio Luiz. Hermenêutica jurídica em crise:uma exploração hermenêutica da construção do Direito.11.ed. Porto Alegre: Livraria do Advogado, 2014.

Verdade e consenso. Rio de Janeiro: Lumen Juris, 2006.

THOMÉ, Romeu. O princípio da vedação do retrocesso socioambiental no contexto da sociedade de risco. Salvador: JusPodivm, 2014.

VILELA, Bruna Luíza Capellini; FRANÇA, Verônica Maria Ramos do Nascimento. Os métodos interpretativos de Ronald Dworking para solução de conflitos ambientais no ordenamento jurídico brasileiro.In: REIS, Émilien Villas Boas (ORG). Entre a filosofia e o ambiente: bases filosóficas para o direito ambiental. Belo Horizonte: 3i Editora, 2014.

ZUFELATO, Camilo. Controle judicial de políticas públicas mediante ações coletivas e individuais. In: GRINOVER, Ada Pellegrini; WATANABE, Kazuo (Coord.). O controle jurisdicional de políticas públicas. $2^{\mathrm{a}}$ ed. Rio de Janeiro: Editora Forense, 2013. 